\title{
Multicystic Ameloblastoma in Anterior Region of the Mandible treated by Partial Mandibulectomy
}

\author{
${ }^{1}$ Saygo Tomo, ${ }^{2}$ Damaris Sprita da Silva, ${ }^{3}$ Mariângela Borghi Ingraci de Lúcia, ${ }^{4}$ Mônica Kina \\ ${ }^{5}$ Karina Gonzales Camara Fernandes, ${ }^{6}$ Luciana Estevam Simonato
}

\begin{abstract}
Among all odontogenic tumors, multicystic ameloblastoma stands out as the most common one, originating from odontogenic epithelium, and despite these tumors are considered benign in nature, it shows a wide aggressive behavior, growing through the trabeculae of spongy bone. Diagnosing multicystic ameloblastoma is frequently challenging, nevertheless, modern imaginologic advents have demonstrating high accuracy. Due to its locally invasive behavior, management of multicystic ameloblastoma has been theme for controversies in literature, nevertheless, most of researches seem to agree that aggressive surgical resection is the most effective approach for this tumor. This paper reports an uncommon case of multicystic ameloblastoma occurring in the anterior mandible region of a female patient. Clinical main manifestation consisted on an extensive swelling in chin region, associated to a bone expansion in anterior lower alveolar bone. The patient reported the lesion has growing slowly, and have not manifested any episode of pain or sensitivity loss. Panoramic radiography analysis revealed an extensive lesion with honeycomb aspect in mental region of the mandible, while the computed tomography analysis showed the vestibular expansion of the tumor with several osseous septa into the lesion. Chosen treatment for the tumor was the partial mandibulectomy incorporation a risk-free bone border, aiming to avoid recurrence, once the literature points high rates of recurrence in ameloblastic tumors conservatively treated. After tumor removal with a 1.5 $\mathrm{cm}$ safe bone, histologic analysis revealed no tumor tissue presence on health bone margin, establishing a good prognosis with no recurrence. Moreover, diagnosis performed based on clinical-radiographical evaluation was satisfactory, leading us to the right diagnosis. This case elucidates that clinical and imaginologic evaluation of ameloblastoma tumors is reliable for clinicians to define the right diagnosis for these lesions. Furthermore, it shows multicystic ameloblastoma might be treated by partial mandibulectomy with a magin of healthy bone with low recurrence chances and satisfactory quality of life.
\end{abstract}

Keywords: Multicystic ameloblastoma, Odontogenic tumors, Partial mandibulectomy.

\footnotetext{
${ }^{1,2}$ Student, ${ }^{3-6}$ Professor

${ }^{1-6}$ Department of Dentistry School, Camilo Castelo Branco University, Fernandópolis, São Paulo, Brazil
}

Corresponding Author: Saygo Tomo, Student, Department of Dentistry School, Camilo Castelo Branco (University), Litério Grecco, 600, 15600-000, Fernandópolis, São Paulo, Brazil Phone: +553499308329, e-mail: saygo.18@hotmail.com
How to cite this article: Tomo $S$, da Silva DS, de Lúcia MBI, Kina M, Fernandes KGC, Simonato LE. Multicystic Ameloblastoma in Anterior Region of the Mandible Treated by Partial Mandibulectomy. World J Dent 2016;7(1):36-40.

Source of support: Nil

Conflict of interest: None

\section{INTRODUCTION}

Odontogenic tumor is a term widely used to describe an uncommon and complex group of lesions which develops on jaws with different histological types and clinical behavior, originating from some aberration during odontogenesis normal development, since they are derived from epithelial, ectomesenchymal or both tissues, which participate of tooth formation. ${ }^{1-3}$ Some of these lesions, from a biological perspective, might represent hamartomas with several differentiation degrees, while the rest might be benign or malignant neoplasms. ${ }^{4}$ Prevalence rates for these lesions range from 1.3 to $5.78 \%$, varying according to the sample studied. ${ }^{3-6}$

Among odontogenic tumors, ameloblastoma is an aggressive tumor of odontogenic epithelial origin, stands out as the most prevalent, representing $1 \%$ of all tumors and cystic lesions of the jaws, and at least $11 \%$ of all odontogenic tumors, manifesting more commonly in the fourth and fifth decades of life and showing no significant predilection for gender or ethnic group, although some studies have showed a slight higher prevalence among male patients. ${ }^{7-9}$ Ameloblastoma tumors are clearly more common in the mandible when compared to maxilla, and about $70 \%$ occur in the molar/ramous region while tumors in the anterior region of the mandible are rare, representing only $10 \%$ of all ameloblastomas in mandible. ${ }^{6,7}$

Ameloblastoma is a locally-invasive neoplasia which develops from the odontogenic epithelium, and is also classified into three clinical-radiographic patterns: (1) solid, conventional or multicystic, (2) unicystic and (3) peripheral. The multicystic type is the most prevalent, and due to its greatest infiltrative potential, this variant stands out as the most aggressive one. However, the occurrence of distant metastasis in multicystic ameloblastoma cases are rare. ${ }^{1,10}$ 
Clinically, multicystic ameloblastoma most common feature is the swelling, nevertheless, in more advanced cases, patient might relate pain or paresthesia of the affected site and show up with dental mobility or even missing teeth. Radiographically, tumors are noticed as multilocular radiolucent lesions, and might present as two patterns: (1) Bubble soap appearance, when there are big radiolucent lobules; (2) honeycomb appearance, when radiolucent lobules appear smaller. These aspects are result of multiple septa of bone tissue remaining into the tumor. Histologically, lesions are variable, showing several histological patterns, but generally, with a remarkable trend to present as cystic alterations. ${ }^{1,2,11}$

The most accepted treatment for ameloblastoma is the surgical resection with a margin of healthy bone tissue, once studies has proved that, due to its locally-infiltrative behavior, multicystic ameloblastoma tumors treated by enucleation followed by curettage clearly tend to recur, while in lesions treated by surgical resection recurrence chances are fewer, since there is no remaining lesion tissue into the bone. ${ }^{12,13}$

The aim of this paper is to present a multicystic ameloblastoma case on a female patient, occurring in the region of mandibular symphysis, which was treated by partial mandibulectomy.

\section{CASE REPORT}

A 55 years old female patient, namely Mulatto, appeared for professional evaluation with a main complaint of a volumetric increase in chin region, which has growing slowly and did not manifest any episode of pain or paresthesia. Medical history was non-contributory, once the patient had no systemic commitment and reported to do not make use of any medication. Dental history revealed she was edentulous and used total prosthesis.

Extraoral examination revealed an extensive rounded swelling with hard consistence, suggesting osseous lesion, in mental region (Fig. 1A), while the intraoral examination showed a discreet hard swelling in the lower vestibule, with a small erosion in the superficial mucosa (Fig. 1B). A

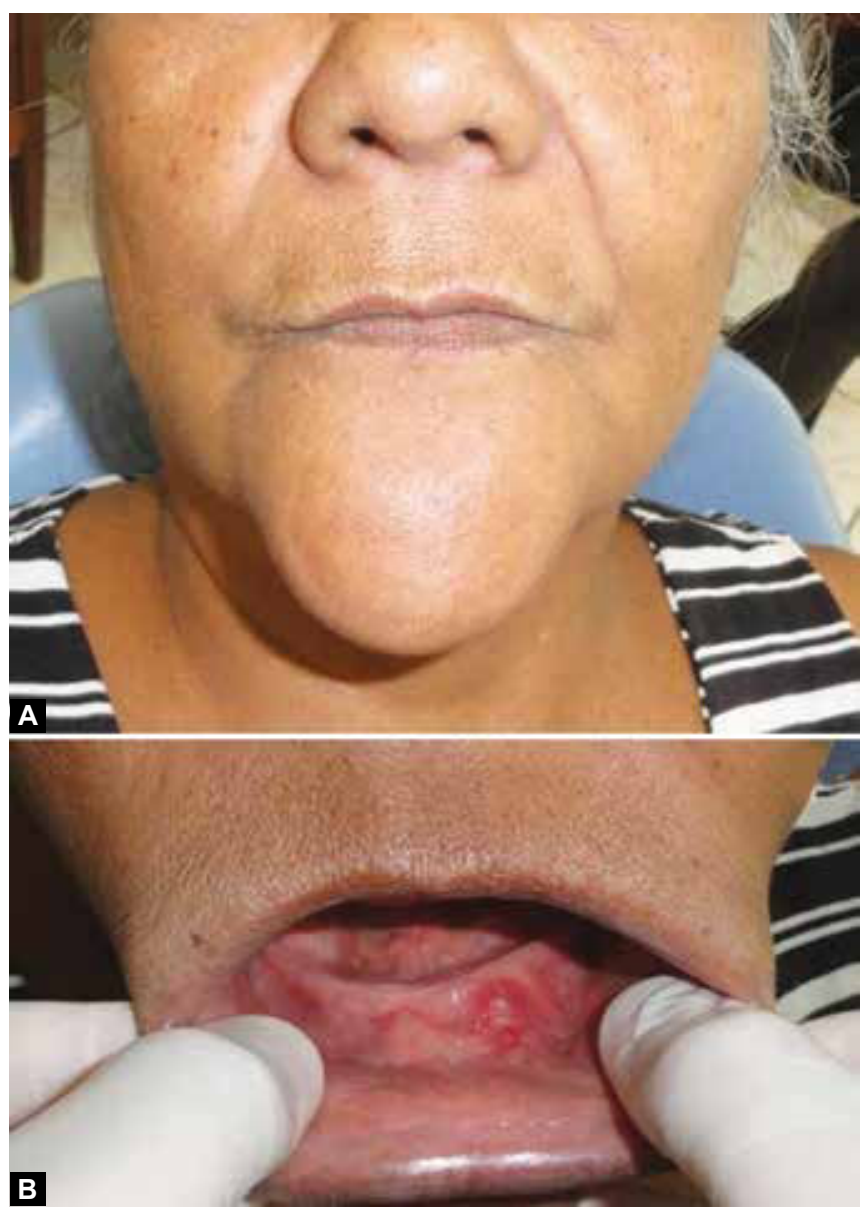

Figs 1A and $B$ : (A) Extraoral round swelling in chin region and (B) intraoral swelling with traumatic lesion by removable prosthesis

panoramic radiography and also a computed tomography (CT) were required. The panoramic radiography (Fig. 2A) revealed an extensive radiolucent lesion covering the whole mental region with honeycomb aspect while the CT showed the vestibular expansion with several osseous septa into the lesion (Figs 2B and C). Based on clinical and radiographic findings, we gave a presumptive diagnosis of multicystic ameloblastoma.

The chosen treatment for the tumor was the partial mandibulectomy under general anesthesia, which was realized by extraoral access, revealing a massive tumor with a smooth surface measuring $4.7 \times 4.6 \times 3.8 \mathrm{~cm}$, and
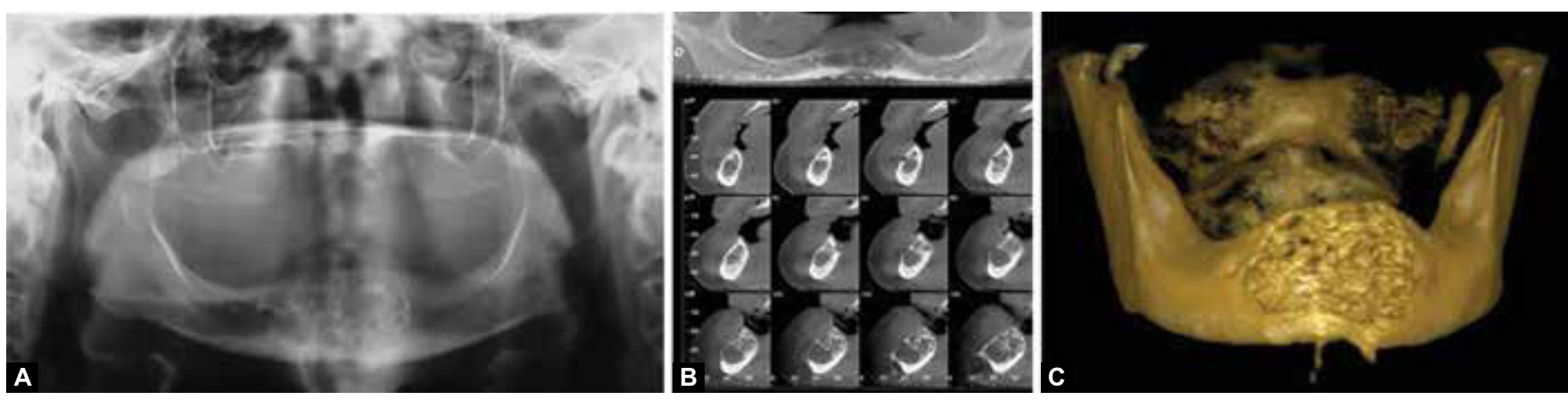

Figs 2A to C: (A) Panoramic radiography showing honeycomb pattern lesion in anterior mandible region, (B) sagittal sections of the lesion on computed tomography and $(\mathrm{C})$ computed tomography 3D reconstruction of the mandible 


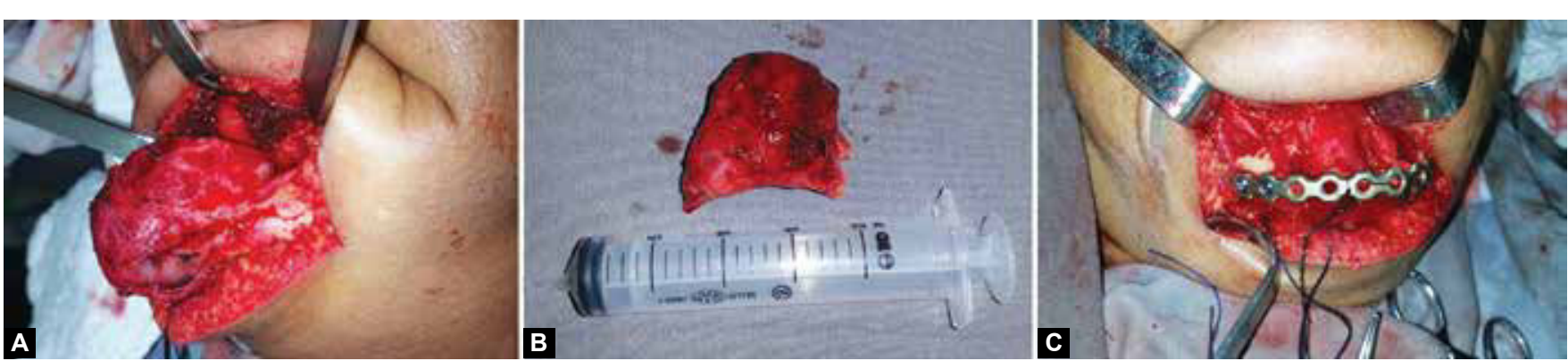

Figs 3A to C: (A) Tumor surgical exposure, (B) tumor removed with healthy bone margins and $(C)$ installation of the titanium plate

a solid cystic lesion on its middle portion, which showed ovate shape and brownish in color (Fig. 3A). The lesion removal was performed, with a margin of approximately $1.5 \mathrm{~cm}$ of clinically healthy bone (Fig. 3B), resulting in the mandible continuity loss, which was fixed with a titanium plate (Fig. 3C). The histopathological analysis was performed after the surgical procedure, confirming the diagnosis for ameloblastoma, and revealing the acanthomatous pattern of the lesion. Histopathological analysis also confirmed the absence of neoplasia in the margin of healthy bone removed with the tumor.

The loss of the related swelling after the surgical procedure is noticed in Figure 4, acquired on the 14th postoperatory day.

\section{DISCUSSION}

As defined by the World Health Organization (WHO), ameloblastoma is a polymorphic neoplasia locallyinvasive which generally shows a follicular or plexiform histologic pattern, constituted by an odontogenic epithelium proliferation and a fibrous stroma, what means these lesions originates from the epithelium which relates to the tooth formation, in other words, from cells capable of develop dental tissues. Potential sources from which ameloblastoma may begin include remaining cells from dental organ, epithelium of odontogenic cysts, mainly dentigerous cyst and odontogenic keratocyst, alterations in developing dental organ, basal cells from mucosal epithelium and remaining cells from dental lamina. However, although expression of histochemical markers in these lesions, like proliferating cell nuclear antigen (PCNA) and antigen Ki-67 protein (MKI67), has been studied, factors which might initiate these cells proliferation remain undefined. As related before, ameloblastomas may also be classified according to the clinical-radiographical behavior of the tumor, being the solid, or multicystic, the most common, and due to its greatest infiltrative potential, this type may also be more aggressive than unicystic and peripheral types. ${ }^{1,2,10,14}$

According to literature, ameloblastoma is the most common odontogenic tumor with variable prevalence

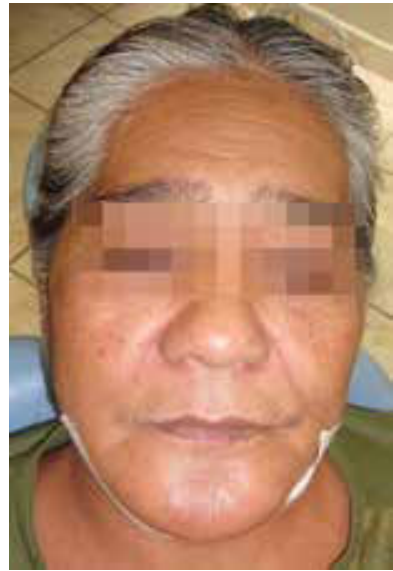

Fig. 4: Fourteenth postoperative day

rates reported, nevertheless some studies have shown this lesion may be responsible for approximately 40,83 to $43 \%$ of all odontogenic tumors, ${ }^{3,4,15}$ and although some authors have reported no significant differences between gender, a slight predilection by the male gender is persistent, with prevalence rates around 52.5 to $67.8 \%$, 616 what does not corroborate with the present case, which in the affected patient is female. However, this case lays with literature data which reports ameloblastoma as more common in men when they are in an younger age while in women it is more common in an older age, once the patient in question is 55 years old, anyway, mean age related in literature is around 39 years old ${ }^{4,6,17}$ This case also stands out by occurring in mandible anterior region because although the mandible is widely more affected than the maxilla, the majority of ameloblastoma tumors occur in mandible posterior region. ${ }^{4,6,7}$

In this case, we got to multicystic ameloblastoma diagnosis based on lesion's history, associated to clinical aspect and imaging tests, what may seem imprecise, once we did not employ biopsy aiming the diagnosis confirmation before surgical resection. Although biopsy has been related as the most reliable test to get to the right diagnosis in ameloblastoma cases, if performed before the surgery, it might bring patient further morbidity, besides, to obtain enough tissue for analysis is either difficult. Therefore, our diagnosis was based on study released by Li et $\mathrm{al}^{18}$ (2012), which in authors reported radiographic 
examinations might be used for determining diagnosis and the treatment planning for ameloblastoma tumors once these radiographs may provide information like bone destruction, bone reaction, lesions edge and further details, such as location and tumor size, and according to review by López-Alvarenga et al ${ }^{12}$ (2010), CT not only allows to define the lesion type, but also to observe invasion degree in affected bone. Nevertheless, Hertog et $\mathrm{al}^{19}$ (2012) found no significant difference between histological subtypes of ameloblastoma and demographical and clinical parameters, neither between histological subtype and treatment outcomes, suggesting histopathological analysis before surgical treatment does not influence significantly on diagnosis neither on treatment plan. Thus, in the present case, the association of clinical and radiographical findings led us to the right diagnosis, which was confirmed by tumor histopathologic analysis performed after its removal. This analysis revealed the acanthomatous pattern of the tumor, which shows extensive squamous metaplasia, often associated to keratin formation in the center of epithelial islands, and, although this is not the most aggressive type, might be confused with squamous cell carcinoma. ${ }^{1}$ However, this analysis was not important to define the diagnosis, but was of great value to patient's prognosis by confirming the total absence of neoplastic tissue in the healthy bone margins, becoming scarce the recurrence chances.

As previously described, multicystic ameloblastoma is a lesion with a broad locally-infiltrative potential by growing trough spongy bone trabeculae, thus, treatment choice causes some controversies in literature. Hasegawa et $\mathrm{al}^{20}$ (2013) defend that a conservative treatment for ameloblastoma, which consists in enucleating followed by lesion curettage, is considerable based in lower recurrence rate of $48.7 \%$, what is still worrying, while most of studies has proposed surgical resections with a $1.5 \mathrm{~cm}$ clinically healthy bone margin, and showing recurrence rates for ameloblastomas treated by enucleation higher than $60 \%,^{12,13}$ thus, in order to prevent any recurrence, treatment chosen for this case was the partial mandibulectomy, which was successful, once, as related before, healthy bone margins removed with the tumor histopathologic analysis showed no neoplastic tissue signals. In review by Gomes et al ${ }^{21}$ (2006), authors reported that, generally, scientific community has tending to realize conservative surgical procedures, aiming to ensure the patient's quality of life. Nevertheless, in more recent review performed by Roy et $\mathrm{al}^{22}$ (2014), authors concluded surgical resection with a risk-free bone border is ideal for the management of multicystic ameloblastoma tumor, effectively preventing possible recurrences.

\section{CONCLUSION}

Multicystic ameloblastoma is an uncommon benign neoplasia developing from the epithelium related to tooth formation that might be diagnosed based on clinical and imaginologic examination and successfully treated by surgical resection, showing better results than the conservative treatment.

\section{REFERENCES}

1. Chi AC. Patologia epitelial. In: Neville BW, et al Patologia oral e maxilofacial. 3rd ed. Rio de Janeiro: Elsevier; 2009. p. 363-453.

2. Morales-Navarro D. Ameloblastoma: Revisión de la literatura. Rev Cub Estomatol 2009;46(3):48-61.

3. Varkhede A, Tupkari JV, Sardar M. Odontogenic tumors: a study of 120 cases in an Indian teaching hospital. Med Oral Patol Oral Cir Bucal 2011;16(7):895-899.

4. Saghravanian N, Jafarzadeh H, Bashardoost N, Pahlavan N, Shirinbak I. Odontogenic tumors in an Iranian population: a 30-year evaluation. J Oral Sci 2010;52(3):e391.

5. da-Costa DOP, Maurício AS, de-Faria PAS, da-Silva LE, Mosqueda-Taylor A, Lourenço SQC. Odontogenic tumors: a retrospective study of four Brazilian diagnostic pathology centers. Med Oral Patol Oral Cir Bucal 2012;17(3):e389.

6. Selvamani M, Yamunadevi A, Basandi PS, Madhushankari GS. Analysis of prevalence and clinical features of multicystic ameloblastoma and its histological subtypes in South Indian sample population: a retrospective study over 13 years. J Pharm Bioallied Sci 2014;6(1):e131.

7. Ebenezer V, Ramalingam B. A cross-sectional survey of prevalence of odontogenic tumours. J Maxillofac Oral Surg 2010;9(4):e369.

8. DeVilliers P, Suggs C, Simmons D, Murrah V, Wright JT. Microgenomics of ameloblastoma. J Dent Res 2011;90(4):e463.

9. Valls A, Montané E, Bescós C, Saez M, Munill M, Alberola M. Manejo quirúrgico del ameloblastoma. Rev Esp Cir Oral Maxilofac 2012;34(3):98-104.

10. Lagares D, Cossio P. Ameloblastoma mandibular: revisión de la literatura y presentacion de seis casos. Med Oral Patol Oral Cir Bucal 2005;10:231-238.

11. Rastogi V, Pandilwar PK, Maitra S. Ameloblastoma: an evidence-based study. J Maxillofac Oral Surg 2010;9(2):e173.

12. López-Alvarenga R, Chrcanovic BR, Horta MCR, Souza LN, Freire-Maia B. Ameloblastoma multiquístico mandibular tratado con terapia menos invasiva: Caso clínico y revisión de la literatura. Rev Esp Cir Oral Maxilofac 2010;32(4):172-177.

13. Dandriyal R, Gupta A, Pant S, Baweja HH. Surgical management of ameloblastoma: conservative or radical approach. Natl J Maxillofac Surg 2011;2(1):e22.

14. Bologna-Molina R, Mosqueda-Taylor A, Molina-Frechero N, Mori-Estevez AD, Sánchez-Acuña G. Comparison of the value of PCNA and Ki-67 as markers of cell proliferation in ameloblastic tumor. Med Oral Patol Oral Cir Buccal 2013;18(2):e174.

15. Mamabolo M, Noffke C, Raubenheimer E. Odontogenic tumours manifesting in the first two decades of life in a rural 
African population sample: a 26 years retrospective analysis. Dentomaxillofac Radiol 2011;40(6):e331.

16. França LJDL, Curioni OA, Paiva DL, Vianna DM, Dedivitis RA, Rapoport A. Ameloblastoma demographic, clinical and treatment study: analysis of 40 cases. Braz J Otorhinolaryngol 2012;78(3):e38.

17. Figueiredo NR, Dinkar AD, Meena M, Satoskar S, Khorate M. Ameloblastoma: a clinicoradiographic and histopathologic correlation of 11 cases seen in Goa during 2008-2012. Contemp Clin Dent 2014;5(2):e160.

18. Li Y, Han B, Li LJ. Prognostic and proliferative evaluation of ameloblastoma based on radiographic boundary. Int J Oral Sci 2012;4(1):e30.
19. Hertog D, Bloemena E, Aartman IH, van-der-Waal I. Histopathology of ameloblastoma of the jaws: some critical observations based on a 40 years single institution experience. Med Oral Patol Oral Cir Bucal 2012;17(1):e76.

20. Hasegawa T, Imai Y, Takeda D, Yasuoka D, Ri S, Shigeta T, Minamikawa T, Shibuya Y, Komori T. Retrospective study of ameloblastoma: the possibility of conservative treatment. Kobe J Med Sci 2013;59(4):e112.

21. Gomes ACA, Silva EDO, Albert DGM, Lira MFC, Andrade ESS. Conceito atual no tratamento dos ameloblastomas. Rev Cir Traumatol Bucomaxilofac 2006;6(3):9-16.

22. RoyI, Louis A, Verma A, Shetye O. Effective management of ameloblastoma: a review. Int J Contemp Dent Med Rev 2014;2014:1-5. 